\title{
Coronavirus disease 2019 (SARS-CoV-2) and colonization of ocular tissues and secretions: a systematic review
}

\author{
Francesco Aiello $\mathbb{D}^{1} \cdot$ Gabriele Gallo Afflitto $\mathbb{D}^{1} \cdot$ Raffaele Mancino $^{1} \cdot$ Ji-Peng Olivia $\mathrm{Li}^{2} \cdot \mathrm{Massimo}$ Cesareo ${ }^{1} \cdot$ \\ Clarissa Giannini ${ }^{1} \cdot$ Carlo Nucci $^{1}$
}

Received: 6 April 2020 / Revised: 16 April 2020 / Accepted: 22 April 2020 / Published online: 18 May 2020

(c) The Author(s), under exclusive licence to The Royal College of Ophthalmologists 2020

\begin{abstract}
Coronavirus disease 19 (COVID-19) has been described to potentially be complicated by ocular involvement. However, scant information is available regarding severe acute respiratory syndrome-coronavirus-2 (SARS-CoV-2) and ocular structures tropism. We conducted a systematic review of articles referenced in PubMed, Cochrane Library, Web of Science and Chinese Clinical Trial Register (ChiCTR) from December 20, 2019 to April 6, 2020, providing information on the presence of SARS-CoV-2 in cornea, conjunctiva, lacrimal sac, and tears. We excluded ongoing clinical studies as for unobtainable conclusive results. Of 2422 articles, 11 met the inclusion criteria for analysis and were included in the study. None of the studies were multinational. Among the 11 selected papers there were three original articles, one review, four letters, two editorials, and one correspondence letter. Globally, 252 SARS-CoV-2 infected patients were included in our review. The prevalence of ocular conjunctivitis complicating the course of COVID-19 was demonstrated to be as high as $32 \%$ in one study only. Globally, three patients had conjunctivitis with a positive tear-PCR, 8 patients had positive tear-PCR in the absence of conjunctivitis, and 14 had conjunctivitis with negative tear-PCR. The majority of the available data regarding SARS-CoV-2 colonization of ocular and periocular tissues and secretions have to be considered controversial. However, it cannot be excluded that SARS-CoV-2 could both infect the eye and the surrounding structures. SARS-CoV-2 may use ocular structure as an additional transmission route, as demonstrated by the COVID-19 patients' conjunctival secretion and tears positivity to reverse transcriptase-PCR SARS-CoV-2-RNA assay.
\end{abstract}

\section{Introduction}

Coronaviruses (CoVs) are enveloped, non-segmented, positive-sense RNA viruses belonging to the family of Coronaviridae [1]. Although they were not considered as highly pathogenic, mostly causing mild infections in immunocompetent people, in the last 20 years they have been responsible for the outbreak of two epidemic, zoonotic, and respiratory syndromes. In 2002 and 2003

Supplementary information The online version of this article (https:// doi.org/10.1038/s41433-020-0926-9) contains supplementary material, which is available to authorized users.

Francesco Aiello

francescoaiello@hotmail.com

1 Ophthalmology Unit, Department of Experimental Medicine, University of Rome "Tor Vergata", Rome, Italy

2 Moorfields Eye Hospital NHS Foundation Trust, London, UK
CoVs were responsible of the severe acute respiratory syndrome (SARS) [2-6] and in 2012, of the Middle East Respiratory Syndrome (MERS) [7, 8]. Altogether, they have caused more than 10,000 cumulative cases, with mortality rates of $10 \%$ for SARS-CoV, and $37 \%$ for MERSCoV [9].

In more recent times, another $\mathrm{CoV}$ hit the headlines for having been described as the cause of a cluster of pneumonia cases in Wuhan, Hubei, China, from December 2019 [9, 10]. On January 31, 2020, the outbreak has been declared by the World Health Organization (WHO) as a Public Health Emergency of International Concern [11]. On February 11, 2020, the WHO officially named the infection due to the virus as coronavirus disease 2019 (COVID-19) [12]. The Coronavirus Study Group of the International Committee on Taxonomy of Viruses named the etiologic agent of COVID-19 as "severe acute respiratory syndrome related coronavirus 2", or SARS-CoV-2 [13]. On March 11, 2020, the WHO declared COVID-19 a pandemic. As of April 06, 2020, a total of 1,136,862 laboratory-confirmed 
cases had been documented, with 63,025 confirmed deaths, in 208 countries [14].

SARS-CoV, MERS-CoV, and SARS-CoV-2 etiologic agents belong to the subfamily of betacoronavirus. Interestingly, both SARS-CoV and SARS-CoV-2 uses angiotensin converting enzyme-2 (ACE2) receptor to primarily infect ciliated bronchial epithelial cells and type 2 pneumocytes [15-17]. In addition, it has been shown that SARSCoV and Human Coronavirus NL63 (HCoV-NL63) infections are associated with conjunctivitis, hence suggesting that $\mathrm{CoV}$ can shed and even infect ocular tissue [18-20].

However, it is still unclear if SARS-CoV-2 can infect or spread through the mucous membranes of the eye. This systematic review will firstly attempt to analyse the current knowledge on SARS-CoV-2 colonization of ocular and periocular tissues and secretions (i.e., cornea, conjunctiva, lacrimal sac, and tears), in order elucidate if conjunctival transmission occurs, and secondarily aims to propose a potential diagnostic tool in the evaluation of suspected, infected patients.

\section{Materials and methods}

We performed a systematic review of the Medline (PubMed), Cochrane Library, World of Science (WoS), and Chinese Clinical Trial Register (ChiCTR) [21] from December 2019 to April 05, 2020 to find papers providing information on the presence of SARS-CoV-2 in cornea, conjunctiva, lacrimal sac, and tears (view "Supplementary Material"). PRISMA guidelines were used for this systematic review [22]. Reference lists of identified articles were independently hand-searched by two authors (GGA, CG). Abstracts were examined, and if eligible, full texts and associated reference lists underwent further evaluation for eligibility. The search was then expanded using a snowballing method applied to the references of retrieved papers, which, once identified, were also screened for accordance to our inclusion criteria. Authors were contacted when necessary. All the results were merged using the reference management software Mendeley (V.1.19.4, Mendeley Ltd). All publications were then reassessed by a third reviewer (FA). According to Cohen's Kappa, interrater agreement was excellent $(\kappa=1)$. Notably, though the majority of publications on COVID-19 are from Asia, no language restrictions were imposed, in order to minimize language bias. Due to the scant evidence, both original articles, editorials, letters, and reviews providing evidence (i.e., prevalence, anecdotal report) about SARS-CoV-2 colonization of ocular and periocular tissues and secretions were all included in the study. In addition, both published and unpublished papers were examined in our analysis, but we excluded ongoing clinical studies as for unobtainable conclusive results. To assess risk of bias and quality of primary studies or systematic reviews identified from database searches, we used the Newcastle-Ottawa Scale for cohort studies, the highest score on which is 9 points [23]. After extensive discussion among reviewers, we decided to include also studies with high risk of bias. We did not register the systematic review protocol because we anticipated the paucity of available information on the subject and due to the urgency of the matter.

\section{Results}

The initial search identified 2422 articles (2403 from PubMed, 0 from Cochrane Library, 15 from WoS, 0 from ChiCTR, and 4 through other sources). Following the initial screening of titles, abstracts and removal of duplicates, we included 11 articles in our review. None of the studies was multinational. Among the 11 selected papers there were three original articles, one review, four letters, two editorials, and one correspondence letter (Table 1) [24-33]. Because of the heterogeneity of studies, no meta-analysis was performed.

$\mathrm{Wu}$ et al. investigated ocular manifestations and viral prevalence in the conjunctiva of 38 patients with COVID19 (mean age: $65.80 \pm 16.60$ years). Among them, 12 eyes $(31.58 \%)$ presented with signs suggestive of conjunctivitis and 2 up to 38 conjunctival specimens (5.26\%) yielded positive findings for SARS-CoV-2 at RT-PCR. Notably, the two positive conjunctival swabs $(2 / 12,16.66 \%)$ were sampled from patients with ocular symptoms [32].

Fang et al. enrolled 32 COVID-19 patients (age range from 34 to 54). They collected nasal, blood, faecal, urine, saliva, and tears samples to detect SARS-CoV-2 RNA via RT-PCR. Conjunctival swabs resulted as positive in five samples (15.63\%). Remarkably, the presence of conjunctivitis or other ocular manifestation was not reported in their letter [33].

Mungmungpuntipantip and Wiwanitkit in their letter to editor did not report any ocular manifestation among the 48 patients met in their practice. However, no conjunctival swab has been sampled and analysed [34].

$\mathrm{Xia}$ et al. attempted to elucidate in a prospective study the presence of the novel coronavirus in conjunctival secretions of confirmed SARS-CoV-2-infected patients at the First Affiliated Hospital of Zhejiang University from January 26, 2020 to February 9, 2020. Authors tested a total of 60 tear samples and conjunctival secretion samples from 30 patients (mean age $=54.50 \pm 14.17$ years). Reversetranscription polymerase chain reaction (RT-PCR) assay resulted positive for SARS-CoV-2 RNA in two swabs (2/ $60,3.33 \%$ ) from a single patient with conjunctivitis symptoms. The other 58 samples yielded negative RT-PCR 


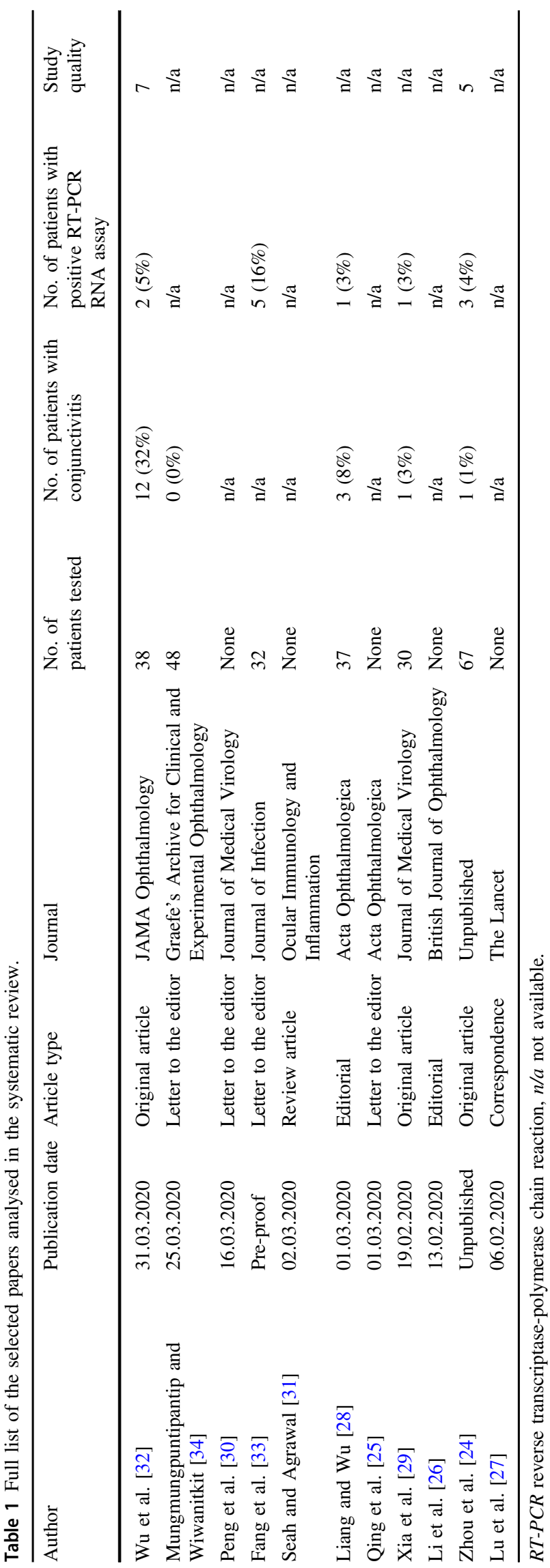

results $(58 / 60,96.66 \%)$ and did not show signs of conjunctivitis [29].

Zhou et al. conducted a similar prospective study at Renmin Hospital of Wuhan University from 17 Jan to 28 Jan 2020 on 67 COVID-19 patients (mean age: $35.70 \pm 10$ years; male/female ratio of 1/1.68). Authors demonstrated conjunctival swab samples positive for SARS-CoV-2-RNA in one and weakly positive in two patients $(3 / 67,4.48 \%)$. None of the aforementioned patients had conjunctivitis at the time of conjunctival swab collection. In the single patient with conjunctivitis, conjunctival swab was negative for RT-PCR (1/67, 1.50\%) [24].

Liang and $\mathrm{Wu}$ analysed 37 conjunctival swabs from confirmed SARS-CoV-2-infected patients at Yichang Central People's Hospital, Hubei. Three out of 37 patients $(8.11 \%)$ had conjunctivitis. Only one swab $(1 / 37 ; 2.70 \%)$ from a severe patient (as for the Chinese COVID-19 diagnosis protocol [9]) not suffering from conjunctivitis, had positive RT-PCR assay [28].

Peng and Zhou, due to the aforementioned contrasting results, described conjunctivitis as a "coincident event, rather than a causal event of SARS-CoV-2 infection of the conjunctiva."[30].

Qing et al. speculated the possibility that SARS-CoV-2, as a droplet, could mix with tears, and then access the respiratory tract via the nasolacrimal duct, further suggesting that conjunctivitis during the course of COVID-19 may be an incidental event [25].

Li et al. strongly suggests physician to "take particular care when examining patients, because of both the proximity to patients' nose and mouth, and the potential exposure to tears which may contain the virus" [26, 35]. This hypothesis was used to suggest the need for ophthalmologist to wear goggles during clinical encounter, as expressed by Lu et al. and Li et al. [26, 27].

However, as analysed by Seah and Agrawal, not only is it still unclear whether SARS-CoV-2 may colonize ocular tissue, but we may also speculate upon other ocular manifestations based on the confirmed expression of ACE2 in different other structures of the eye [24, 30, 31].

\section{Discussion}

To the best of our knowledge this is the first systematic review summarizing all the data regarding SARS-CoV-2 colonization of ocular and periocular tissues and secretions (i.e., cornea, conjunctiva, lacrimal sac, tears).

This systematic review analysed 252 SARS-CoV-2infected patients globally who underwent conjunctival swab, and demonstrates the prevalence of ocular conjunctivitis complicating the course of COVID-19 to be as high as $32 \%$ (12 patients out 38), differently as what 
previously stated by the "Report of the WHO-China Joint Mission on Coronavirus Disease 2019 (COVID-19)" as low as $0.8 \%$ [36]. Altogether, three patients had conjunctivitis with a positive tear-PCR, eight patients had positive tearPCR in the absence of conjunctivitis, and 14 had conjunctivitis with negative tear-PCR [24, 28, 29, 32, 33]. This inconsistency may be due to a number of factors, including low viral load in conjunctival secretion, inappropriate sample collection or handling leading to sample contamination, and damage to genetic material. Though current RT-PCR is considered an effective technique, it could inevitably lead to false positive and false negative results [37, 38].

The caution for potential ocular transmission of SARSCoV-2 was first highlighted by one of the experts of the task force who visited Wuhan on early 2020. Despite being fully gowned with protective coat and N95 mask, he was still infected and reported his first symptom being unilateral conjunctivitis, with subsequent fever and catarrhal symptoms 2-3 hours later. The latency period of a few hours from conjunctivitis to respiratory symptoms does not aide in the determination of the route of transmission, since the virus may have entered via the unshielded ocular surface and caused respiratory symptoms around the same time as conjunctivitis, but masking may also have been ineffective, and conjunctivitis was merely a manifestation of SARSCoV2. It would be useful to further elucidate SARS-CoV-2 binding to the surface of ocular tissues. It has been shown that SARS-CoV-2 cell entry depends on SARS-CoV-2 S protein/ACE2 receptor interaction [39]. Key proteins crucial to the renin-angiotensin-aldosterone system (RAAS) have been widely described in many ocular structures, including the aqueous [40], the pigmented epithelium [41], and the retina [31, 42-45].

Evidence of the expression of such proteins both in the conjunctiva and in the cornea are limited. The only study trying to address this question with an in vitro model demonstrated ACE2 expression on both corneal and conjunctival cells and also showed effective binding of the S240 proteins of SARS-CoV with ACE2 receptor on both cells and tissues [46].

Furthermore, given the high vascularity of conjunctiva, along with the expression of ACE2 on the surface of endothelial cells [44, 45], it cannot be excluded that the ocular manifestation of SARS-CoV-2 infection may in fact manifest in the form of a local, transient vasculitis [47].

Due to the presence of RAAS proteins expression in different ocular tissues, it can also be speculated that, even in the form of anecdotal event, SARS-CoV-2 may be responsible for other possible ocular manifestations as anterior or posterior uveitis, iridocyclitis, vitritis, or retinal vasculitis [31, 40, 42-45].
Given the scarce nature of the available evidence regarding SARS-CoV-2 transmission through ocular tissue, no conclusions could be reached either regarding its ability to infect ocular structures or to use the lacrimal duct to reach the respiratory tract, as a novel transmission route [25].

In addition, due to inconsistency in RT-PCR assay results, conjunctival-swab RT-PCR should not be proposed as a standard diagnostic technique for COVID-19.

As it emerged from this analysis, evidence is not only limited, but sorely conflicting too, which determines low strength of the actual available data. In fact, no comparable results emerged in terms of both mean age at recruitment, number of recruited patients, and male/female ratio. In the two original articles and in the editorial reporting clinical data, only RT-PCR was run, while none of the studies reported viral culture [24, 28, 29]. Hence, it cannot be established whether SARS-CoV-2 only colonizes ocular structure or it is able to invade them, inducing conjunctivitis.

It is desirable that, as the current pandemic continues, a better understanding of the viral features with a focus on the viral tropism for ocular structures will emerge.

In the meantime, physicians should stay highly vigilant in recognizing patients with any previous contact at risk and early manifestation of COVID-19, including systemic symptoms and fever. A specific consideration must be dedicated to any ocular inflammatory involvement as a possible presentation. Individual protection kits including goggles are strongly recommended, especially in at risk clinical encounters [35, 48, 49].

\section{Compliance with ethical standards}

Conflict of interest The authors declare that they have no conflict of interest.

Publisher's note Springer Nature remains neutral with regard to jurisdictional claims in published maps and institutional affiliations.

\section{References}

1. Cui J, Li F, Shi ZL. Origin and evolution of pathogenic coronaviruses. Nat Rev Microbiol. 2019;17:181-92.

2. Holmes KV. SARS-associated coronavirus. $N$ Engl J Med. 2003;348:1948-51. http://www.ncbi.nlm.nih.gov/pubmed/12748314.

3. Zhong NS, Zheng BJ, Li YM, Poon LLM, Xie ZH, Chan KH, et al. Epidemiology and cause of severe acute respiratory syndrome (SARS) in Guangdong, People's Republic of China, in February, 2003. Lancet. 2003;362:1353-8.

4. Drosten C, Günther S, Preiser W, Van der Werf S, Brodt HR, Becker $\mathrm{S}$, et al. Identification of a novel coronavirus in patients with severe acute respiratory syndrome. $N$ Engl $J$ Med. 2003;348:1967-76.

5. Fouchier RAM, Kuiken T, Schutten M, Van Amerongen G, Van Doornum GJJ, Van Den Hoogen BG, et al. Koch's postulates fulfilled for SARS virus. Nature. 2003;423:240. 
6. Ksiazek TG, Erdman D, Goldsmith CS, Zaki SR, Peret T, Emery $\mathrm{S}$, et al. A novel coronavirus associated with severe acute respiratory syndrome. N Engl J Med. 2003;348:1953-66.

7. de Groot RJ, Baker SC, Baric RS, Brown CS, Drosten C, Enjuanes L, et al. Middle East respiratory syndrome coronavirus (MERS-CoV): announcement of the coronavirus study group. J Virol. 2013;87:7790-2.

8. Zaki AM, Van Boheemen S, Bestebroer TM, Osterhaus ADME, Fouchier RAM. Isolation of a novel coronavirus from a man with pneumonia in Saudi Arabia. N Engl J Med. 2012;367:1814-20.

9. Huang C, Wang Y, Li X, Ren L, Zhao J, Hu Y, et al. Clinical features of patients infected with 2019 novel coronavirus in Wuhan, China. Lancet. 2020;395:497-506.

10. Guan W, Ni Z, Hu Y, Liang W, Ou C, He J, et al. Clinical characteristics of coronavirus disease 2019 in China. N Engl J Med. 2020. http://www.nejm.org/doi/10.1056/NEJMoa2002032.

11. Eurosurveillance editorial team. Note from the editors: World Health Organization declares novel coronavirus (2019-nCoV) sixth public health emergency of international concern. Euro Surveill. 2020;25:pii 200131e. https://doi.org/10.2807/1560-7917. ES.2020.25.5.200131e

12. World Health Organization. Novel Coronavirus (2019-nCoV) Situation Report-22. 2020. https://www.who.int/docs/defaultsource/coronaviruse/situation-reports/20200211-sitrep-22-ncov. pdf?sfvrsn=fb6d49b1_2.

13. Coronaviridae Study Group of the International Committee on Taxonomy of Viruses. The species Severe acute respiratory syndrome-related coronavirus: classifying 2019-nCoV and naming it SARS-CoV-2. Nature microbiology. 2020;5:536-44.

14. World Health Organisation. Novel coronavirus (COVID-19) situation. 2020. https://experience.arcgis.com/experience/685d0a ce521648f8a5beeeee1b9125cd.

15. Li W, Moore MJ, Vasllieva N, Sui J, Wong SK, Berne MA, et al. Angiotensin-converting enzyme 2 is a functional receptor for the SARS coronavirus. Nature. 2003;426:450-4.

16. Yeo C, Kaushal S, Yeo D. Enteric involvement of coronaviruses: is faecal-oral transmission of SARS-CoV-2 possible? Lancet Gastroenterol Hepatol. 2020;4:335-7.

17. Wang XW, Li J, Guo T, Zhen B, Kong Q, Yi B, et al. Concentration and detection of SARS coronavirus in sewage from Xiao Tang Shan hospital and the 309th Hospital of the Chinese People's Liberation Army. Water Sci Technol. 2005;52:213-21.

18. Van Der Hoek L, Pyrc K, Jebbink MF, Vermeulen-Oost W, Berkhout RJM, Wolthers KC, et al. Identification of a new human coronavirus. Nat Med. 2004;10:368-73.

19. Vabret A, Mourez T, Dina J, Van Der Hoek L, Gouarin S, Petitjean J, et al. Human coronavirus NL63, France. Emerg Infect Dis. 2005;11:1225-9.

20. Loon SC, Teoh SCB, Oon LLE, Se-Thoe SY, Ling AE, Leo YS, et al. The severe acute respiratory syndrome coronavirus in tears. Br J Ophthalmol. 2004;88:861-3.

21. Chinese Clinical Trial Register (ChiCTR). The world health organization international clinical trials registered organization registered platform. 2018:3-4. http://www.chictr.org.cn/enindex. aspx.

22. Moher D, Shamseer L, Clarke M, et al. Preferred reporting items for systematic review and meta-analysis protocols (PRISMA-P) 2015 statement. Syst Rev. 2015;4:1. Published 2015 Jan 1. https:// doi.org/10.1186/2046-4053-4-1.

23. Ottawa Hospital Research Institute. The Newcastle-Ottawa Scale (NOS) for assessing the quality of nonrandomised studies in meta-analyses. 2020. http://www.ohri.ca/programs/clinical_ epidemiology/oxford.asp.

24. Zhou Y, Zeng Y, Tong Y, Chen C. Ophthalmologic evidence against the interpersonal transmission of 2019 novel coronavirus through conjunctiva. medRxiv. 2020:2020.02.11.20021956.
25. Qing H, Li Z, Yang Z, Shi M, Huang Z, Song J, et al. The possibility of COVID-19 transmission from eye to nose. Acta Ophthalmol. 2020. http://www.ncbi.nlm.nih.gov/pubmed/32189463.

26. Li JPO, Lam DSC, Chen Y, Ting DSW. Novel Coronavirus disease 2019 (COVID-19): the importance of recognising possible early ocular manifestation and using protective eyewear. $\mathrm{Br} \mathrm{J}$ Ophthalmol. 2020;104:297-8. http://www.ncbi.nlm.nih.gov/ pubmed/32086236.

27. Lu C, Liu X, Jia Z. 2019-nCoV transmission through the ocular surface must not be ignored. Lancet. 2020;395:e39. https:// linkinghub.elsevier.com/retrieve/pii/S0140673620303135.

28. Liang $\mathrm{L}, \mathrm{Wu} \mathrm{P}$. There may be virus in conjunctival secretion of patients with COVID-19. Acta Ophthalmol. 2020. http://doi. wiley.com/10.1111/aos.14413.

29. Xia J, Tong J, Liu M, Shen Y, Guo D. Evaluation of coronavirus in tears and conjunctival secretions of patients with SARS-CoV-2 infection. J Med Virol. 2020. https://onlinelibrary.wiley.com/doi/a bs/10.1002/jmv.25725.

30. Peng Y, Zhou Y-H Is novel coronavirus disease (COVID-19) transmitted through conjunctiva? J Med Virol. 2020. http://www. ncbi.nlm.nih.gov/pubmed/32176356.

31. Seah I, Agrawal R. Can the Coronavirus Disease 2019 (COVID19) affect the eyes? A review of coronaviruses and ocular implications in humans and animals. Ocul Immunol Inflamm. 2020;1-5. http://www.ncbi.nlm.nih.gov/pubmed/32175797.

32. Wu P, Duan F, Luo C, Liu Q, Qu X, Liang L, et al. Characteristics of ocular findings of patients with coronavirus disease 2019 (COVID-19) in Hubei Province, China. JAMA Ophthalmol. 2020;2019:4-7. http://www.ncbi.nlm.nih.gov/pubmed/32232433.

33. Fang Z, Zhang Y, Hang C, Zhang W, Ai J, Li S. Comparisons of nucleic acid conversion time of SARS-CoV-2 of different samples in ICU and non-ICU patients. J Infect. 2020. https://doi.org/10. 1016/j.jinf.2020.03.013.

34. Mungmungpuntipantip R, Wiwanitkit V. Ocular manifestation, eye protection, and COVID-19. Graefes Arch Clin Exp Ophthalmol. 2020;4662. http://www.ncbi.nlm.nih.gov/pubmed/32232568.

35. Lai THT, Tang EWH, Chau SKY, Fung KSC, Li KKW. Stepping up infection control measures in ophthalmology during the novel coronavirus outbreak: an experience from Hong Kong. Graefes Arch Clin Exp Ophthalmol. 2020;1-7. http://www.ncbi.nlm.nih. gov/pubmed/32124000.

36. World Health Organisation. Report of the WHO-China Joint Mission on Coronavirus Disease 2019 (COVID-19). 2020. https://www.who.int/publications-detail/report-of-the-who-chinajoint-mission-on-coronavirus-disease-2019-(covid-19).

37. Corman VM, Landt O, Kaiser M, Molenkamp R, Meijer A, Chu DK, et al. Detection of 2019 novel coronavirus (2019-nCoV) by real-time RT-PCR. Eurosurveillance. 2020;25:2000045. https://www.eurosurveillance.org/content/10.2807/1560-7917.ES. 2020.25.3.2000045

38. Lin C, Ye R, Xia YL. A meta-analysis to evaluate the effectiveness of real-time PCR for diagnosing novel coronavirus infections. Genet Mol Res. 2015;14:15634-41.

39. Hoffmann M, Kleine-Weber H, Schroeder S, Mü MA, Drosten C, Pö S, et al. SARS-CoV-2 cell entry depends on ACE2 and TMPRSS2 and is blocked by a clinically proven protease inhibitor article SARS-CoV-2 cell entry depends on ACE2 and TMPRSS 2 and is blocked by a clinically proven protease inhibitor. Cell. 2020;181:1-10. https://doi.org/10.1016/j.cell.2020. 02.052 .

40. Holappa M, Valjakka J, Vaajanen A. Angiotensin(1-7) and ACE2, "The Hot Spots" of Renin-Angiotensin System, detected in the human aqueous humor. Open Ophthalmol J. 2015;9:28-32.

41. Tao L, Qiu Y, Fu X, Lin R, Lei C, Wang J, et al. Angiotensinconverting enzyme 2 activator diminazene aceturate prevents lipopolysaccharide-induced inflammation by inhibiting MAPK 
and NF-kappaB pathways in human retinal pigment epithelium. $\mathrm{J}$ Neuroinflammation. 2016;13:35.

42. Reichhart N, Figura A, Skosyrski S, Strauss O. Control of the retinal local RAS by the RPE: An interface to systemic RAS activity. Experimental eye research. 2019;189:107838.

43. Fletcher EL, Phipps JA, Ward MM, Vessey KA, Wilkinson-Berka JL. The renin-angiotensin system in retinal health and disease: its influence on neurons, glia and the vasculature. Prog Retin Eye Res. 2010;29:284-311.

44. Lovren F, Pan Y, Quan A, Teoh H, Wang G, Shukla PC, et al. Angiotensin converting enzyme-2 confers endothelial protection and attenuates atherosclerosis. Am J Physiol Heart Circ Physiol. 2008;295: H1377-84. http://www.ncbi.nlm.nih.gov/pubmed/18660448.

45. Zhang YH, Zhang Yhuan, Dong XF, Hao QQ, Zhou XM, Yu QT, et al. ACE2 and Ang-(1-7) protect endothelial cell function and prevent early atherosclerosis by inhibiting inflammatory response. Inflamm Res. 2015;64:253-60.

46. Sun Y, Liu L, Pan X, Jing M. Mechanism of the action between the SARS-CoV S240 protein and the ACE2 receptor in eyes. Int J Ophthalmol. 2006;6:783-6. https://www.researchgate.net/publica tion/289011231_Mechanism_of_the_action_between_the_SARSCoV_S240_protein_and_the_ACE2_receptor_in_eyes.

47. Jiang G, Korteweg C. Pathology and pathogenesis of severe acute respiratory syndrome. Am J Pathol. 2007;170:1136-47.

48. Centers for Disease Control and Prevention-CDC. Information for Healthcare Professionals: COVID-19. 2020. https://www.cdc. gov/coronavirus/2019-ncov/hcp/index.html.

49. Chang D, Xu H, Rebaza A, Sharma L, Dela Cruz CS. Protecting health-care workers from subclinical coronavirus infection. Lancet Respir Med. 2020;8:e13. 